\title{
Seven Cases of Gilles de la Tourette's Syndrome: Partial Relief with Clonazepam: A Pilot Study
}

\author{
M. GONCE AND A. BARBEAU
}

SUMMARY: The histories of seven consecurive cases of Gilles de la Tourette's syndrome are presented to exemplify the range of clinical manifestations in this disease and to collate preliminary results with the new benzodiazepine. clonazepam, as a possible adjuvant therapy of this disorder. Controlled trials with clonazepam alone and in association with haloperidol are now justified. Five of out 7 patients had a positive

RÉSÜMÉ: Nous présentons les histoires de cas de sept patients consécutifs atteints du syndrome de Gilles de la Tourette, afin d'illustrer la variété des manifestations cliniques et afin de présenter quelques résultats préliminaires de l'emploi da nouveau benzodiazepine. le clonazepam. comme therapie de somtien dans cette maladie. Ces résultats préliminaires justifient des essais contrôlés avec le clonazepam seal et en association avec l'haloperidol.

Cinq de nos 7 patients présentaient une family history of tics, and 2 a confirmed family history of gout. Because clonazepam improves myoclonia and tics and because its mechanism of action possibly involves serotonin, we thought it worthwhile to study simultaneously the relative roles of serotonin and dopamine metabolism in the production of tics, and their relationship to possible defects in parine metabolism in Gilles de la Tourette's syndrome.

histoire familiale positive pour tics, alors qu' une incidence familiale de goûte était présente chez 2 de nos cas. Parce que le clonazepam est efficace contre les myoclonies ainsi que les tics et parce que son mécanisme d'action implique possiblement la sérotonine, nous suggérons qu'il serait utile d'étudier simultanément les rôles relatifs de la sérotonine et de la dopamine dans la génèse des tics, et leurs relations avec an défaut possible du métabolisme des purines dans le syndrome de Gilles de la Tourette.
From the Department of Neurobiology, Clinical Research Institute of Montreal.

Reprint requests to: Dr. André Barbeau, Department of Neurobiology, Clinical Research Institute of Montreal. 110 Pine Avenue West, Montreal, Quebec H2W IR7.

\section{INTRODUCTION}

Gilles de la Tourette's syndrome is a rare movement disorder frequently misdiagnosed and therefore often inadequately treated. It usually begins between the ages of 2 and 14 with involuntary tic-like muscular movements. The tics are coordinated, rhythmical, purposeless and rapid. Various inarticulate noises and words develop in time. The condition may or may not be associated with coprolalia, which occurs in only $52 \%$ of Tourette patients and therefore is unessential for the diagnosis. Echolalia, palilalia, repetitive touching, mental coprolalia and copropraxia may also occur. Of particular importance in the diagnosis of the illness is the changing pattern of multiple symptoms, one symptom slowly evolving into another. The disease has a fluctuating and insidious course with frequent plateaus and even some remissions (Bruun and Shapiro, 1972; Shapiro et al., 1973; Barbeau, 1975; Gonce and Barbeau, 1977). An early and accurate diagnosis is important since effective treatment with haloperidol is possible in some patients (Seignot, 1967; Chapel et al., 1964; Shapiro et al., 1973). The difficulties with this drug should not be minimized, however, as many failures have been recorded (Shapiro et al., 1973; Di Giacomo et al., 1971; Moldofsky, 1971) and tolerance may develop (Abuzzahab and Ehlen, 1971; Fernando, 1976). We should, therefore, like to report 7 cases of Gilles de la Tourette's syndrome as illustrations of difficulties in therapy and of our preliminary clinical results with clonazepam.

\section{CASE REPORTS}

Case No. I: $L ; M-C$

This 43-year-old woman has 12 siblings; two brothers stutter, 2 sisters have tics and another 
one has tics and stutters. Her mother was deaf and after the patient's birth was placed in a psychiatric institution. Little is known about her early childhood, but developmental milestones seem to have been passed at appropriate intervals. The patient's illness began at age 9 with the onset of throat clearing noises, arm and leg tics and constant hopping. As a sequella of chronic otitis, bilateral deafness appeared at about the same age. Then the condition became chronic with a changing pattern of symptoms, new tics slowly developed and replaced or were added to the previous one: e.g., at times she grunted, or had diaphragmatic tics with suffocation feelings, or a nonproductive cough.

EEG's, X-Rays of the skull and serum biology were normal. Several trials with haloperidol failed because of adverse reactions and she felt most improved from deanol and clonazepam. Presently, the clinical picture is one of constant throat-clearing noises, coughs, jumping motions, shoulder shrugs, torsion of the torso and left arm jerks. The neurological examination also reveals a discrete postural tremor and some dystonic movements of the upper extremities. The patient also tears her hair, as in her childhood, and speaks easily of her incestuous relations with her brother. No definite conclusion about the value of clonazepam in this patient is possible. She failed to follow her treatment regularly and she showed little will to improve, deriving secondary gain from her unusual behavioral patterns. Nevertheless, after taking clonazepam she had less movements of the torso and shoulders, as reported by the patient and confirmed by us and some family members.

\section{Case No. 2: M., C.}

This 13-year-old boy was referred to us in June, 1976. He is the older of two children. The family history reveals antecedents of gout in the paternal grandfather and a half brother of the mother. The maternal grandmother had tics of the eyelids. The patient's birth history was uneventful, early development was normal and his childhood was happy until age 7 when he was brought to his physician for evaluation of hyperactivity. He could not read properly and had learning problems. A disturbance in spatial relationship perception was described, for which he was sent to a special class for two years. He did well and rejoined normal classes in grade 4 . Also at age 7, he began to suffer from tics consisting of jerky movements of the head, eye twitching, facial grimaces, coughing and grunting. Those symptoms waxed and waned until they spontaneously disappeared at age 11-12. At age 10, he consulted a psychiatrist because he was having problems of adaptation in his new school. At this stage, besides the tics, he displayed marked hyperactive behavior; his general attention and frustration tolerance were low. Intellectual functioning, as recorded by the Wisconsin test, indicated verbal performance and full scale I.Q.'s of 116,111 and 115 respectively. In 1975, he returned from summer camp with a bad cough which persisted and he entered middle school, grade 7 . In the fall, he started having jerky movements of the head to the right which varied in frequency, between 25 to 60 per minute. After twenty-four hours he began making blowing noises with his mouth and a few days later he started clearing his throat and then developed a nonproductive cough. The mother did not describe any change in the boy's personality and there was no change in scholastic achievement. Despite treatment with thioridazine (Mellaril $\left.R_{i}\right)$, the symptoms worsened and the boy was hospitalized. Although there was no history of sore throat, fever, myalgia or joint pain and neither physical or laboratory evidence, the child was discharged with the possible diagnosis of Sydenham's chorea and treated by rest and chlorpromazine (Largactil $^{R}$ ) $25 \mathrm{mg}$. twice daily. Some improvement in the abnormal movements, as well as the recently acquired "barking" occurred, but the symptoms were not completely controlled. In December, 1975, he was referred to another neurologist who diagnosed Gilles de la Tourette's syndrome and treatment with haloperidol was started $(1 \mathrm{mg}$., twice daily). This produced a dramatic improvement which, with a maintenance dosage of $3.5 \mathrm{mg}$. daily, lasted until March, 1976. At that time, the symptoms (chiefly barking) re-emerged despite a progressive increase in haloperidol. When we saw him for the first time, he was taking $46.5 \mathrm{mg}$. haloperidol and 6 $\mathrm{mg}$. of biperidene hydrochloride (Akineton ${ }^{R}$ ) daily. The physical examination revealed a hyperactive 13-year-old boy who looked older than his age. He was alert and intelligent, cooperative and constantly moving around. $\mathrm{He}$ had jerky movements of the head, motor tics (snapping) and vocalisations: throat clearings and explosive sharp yelping occurring in spurts of 4 or 5 at irregular intervals. His walking was hesitant and interrupted by jumps. He was right-handed and the rest of the neurological examination was negative, except for a rapid tremor of the hands. Serum uric acid level was elevated $(8.1 \mathrm{mg} . \%)$. In addition to haloperidol and biperidene hydrochloride, he was started on clonazepam 2 mg. twice daily, but the patient could not tolerate this because of ataxia and drowsiness. Therefore, he was treated with progressively increasing doses beginning with $1 \mathrm{mg}$., b.i.d., and adding $0.5 \mathrm{mg}$. to the daily dose weekly. One month later while receiving the same doses of biperidene hydrochloride and haloperidol and $3.5 \mathrm{mg}$. of clonazepam/day, he noticed a decrease in frequency and power of the barks and an attenuation of the motor tics, whereas an old symptom reappeared: facial grimaces 3 or 4 times per day. Drowsiness was less marked, but he was forgetful. An elevation of serum alkaline phosphatase was found at this time. Unfortunately, a gradual increase in the drowsiness forced a reduction in haloperidol over the next few months. With a constant clonazepam dosage, no further improvement was noted, but drowsiness decreased and no worsening occurred. The reduction in dosage is continuing.

\section{Case No. 3: T., D.}

The illness of this 21-year-old married housewife began at age 3 years with facial tics.
The movements then spread insidiously to the neck, the arm and the legs. At times she also had vocalisations (throat clearing noises, shouting), more complicated involuntary movements (jumping, hitting) and repetitive movements (shaking hand). Coprolalia was not present. At the age of fourteen, she had an encephalitis which did not seem to modify the symptoms. During the last 3 years her symptoms worsened, particularly during pregnancy. When we saw her for the first time in January, 1976, she showed constant tics: head twitches, facial grimaces, shoulder shrugs, arm and leg jerks. Vocalizations were not present. Family history revealed her father had facial tics and one of her sisters had childhood tics, whereas a second had constant movements of her hands. No evidence of Huntington's chorea was discovered in the family. Her neurological examination, EEG and blood tests were otherwise normal. The neuropsychological tests did not show any mental deterioration, although some mild deficiency in visuo-motor integration was present. She had previously received haloperidol (6 $\mathrm{mg}$., die). Severe side effects and no improvement caused her to stop it. We started clonazepam at $2 \mathrm{mg}$., die, during one week and $2 \mathrm{mg}$, bid, thereafter. A significant improvement was noticed immediately. There was a decrease in the intensity and frequency of her tics and movements. There was also increased voluntary control of some symptoms without an explosive build-up of other symptoms, as is common in these patients. The few remaining movements were mainly localized to the neck and shoulders with predominance on the right side. The improvement was maintained for about 4 months. Then, she began to lose part of the benefits derived from clonazepam. Her husband claimed she was more aggressive and the tics had increased while the patient still felt some improvement. The dosage was increased to $2 \mathrm{mg}$., tid. Because of ataxia and drowsiness, she stopped the treatment, but the abrupt reemergence of all the symptoms forced her to return to the previous clonazepam regimen. She then decided to be treated by acupuncture and withdrew from the clinical trial.

\section{Case No. 4: B., C.}

This 48-year-old man, separated from his wife, was first seen in January, 1976, because of multiple tics and vocalization. His mother's pregnancy was without complications and early development was normal until the onset of compulsive eye blinking at age 5 or 6 . Soon after the face was involved and progressively the abnormal stereotyped movements spread to the head, the neck and shoulders. Though there were some periods of partial remissions, the tics slowly worsened until age 20 . From that time they seemed to remain stable, although they were exacerbated under social and emotional stress. The grunts he had experienced for short periods of time, became permanent at about ten years of age. He had been treated unsuccessfully by a neurologist and a chiropractor at the age of 12 and thereafter he lived with his condition which did not greatly impair his social and professional life. In the presence of strangers he tried, generally 
without success, to voluntarily control his symptoms. In 1973, he read a paper describing Gilles de la Tourette's syndrome and consulted a psychiatrist who treated him with haloperidol and benztropine (Cogentin ${ }^{R}$ ). Because of akathisia and no improvement he stopped the medication.

When we saw him for the first time, he showed frequent and multiple tics: eye blinking. mouth and lip twitches, right shoulder shrugs, abrupt head movements to the right and more discrete finger and feet jerks. He also grunted, but had no coprolalia. The neurological examination was normal and the patient was left handed. There was no history of tics or other neurological diseases in his family except for his brother who had transient tics of childhood. The blood analysis revealed hyperuricemia $(8.1 \mathrm{mg} . \%$ ), but neither he or his relatives suffered from gout. We first treated him with haloperidol, but again he could not tolerate this because of nervousness and paradoxical increases in tic intensity. We then started treatment with clonazepam $2 \mathrm{mg}$. bid. Three months later, a significant improvement was achieved. The grunts had disappeared and the motor tics showed a 30 to $40 \%$ decrease in intensity and frequency. It is worthwhile to note that partial relief of the symptoms was accompanied by transient aggressiveness toward his family. The dose of clonazepamm was increased to $2 \mathrm{mg}$., tid, without further improvement. The patient appears to be quite satisfied with his present status.

\section{Case No. 5: L., M.}

At the age of one month, this 22-year-old girl suffered from hyperthermic convulsions lasting 10-15 minutes. No immediate sequellae were noted. Thereafter, her mother noticed a delay in motor acquisitions: the patient began walking at age $2 \frac{1}{2}$ and fell frequently until age 7. The mother's description did not suggest ataxia, but rather a normal gait, paroxysmally disrupted, for short intervals. From time to time some dysarthria and echolalia were present. At age 9-10 years the patient experienced the onset of tics mimicking wing flutter, first involving both arms, then gradually restricted to the left side. Later, the gait was interrupted by repetitive right foot tapping. After a period of partial spontaneous remission, at age 18 , the symptoms reemerged accompanied by eye twitches. One year later vocalizations completed the clinical picture. Twenty to 30 times a day, when alone, she emitted high-pitched sounds with subsequent relief of tension. Although she had mild learning difficulties she attended school to grade 12. She is now working in a hotel and suffers from chronic ulcerations of the mouth (without evidence of self-mutilation) and acne for which she receives hormonal medication. This has not modified the course of the illness.

Neurological examination revealed flapping movements of the left arm, gait abnormalities, mild dysmetria and adiadococinesis on the right side (she is left-handed). The most striking features were her abnormal ocular movements: repetitively, the eyes moved up and to the right. She has difficulties turning her eyes to the left. We have also noticed palilalia, sniffing and stammering. When asked to voluntarily control her symptoms, she succeeded with difficulty, but with a subsequent explosive increase in the tics. Blood tests and EEG's were normal. There was no familial history of tics, gout or other neurological or psychiatric disease, but one of her sisters demonstrated transient arm flapping when she was 15-16.

The patient initially received clonazepam, but because of ataxia and drowsiness, even with low doses, she was changed to haloperidol $(0.5 \mathrm{mg}$., bid) which was successful. Most of the tics are now absent.

\section{Case No. 6: R., M.}

This male patient was referred to us when he was 20 years old. His mother probably suffered from tuberculosis during her pregnancy; the labor lasted 12 hours and delivery required forceps under anesthesia. The child had a facial injury, remained cyanotic and because of respiratory difficulties was placed in an incubator for 4.5 days. Early growth was poorly documented by the mother, but developmental milestones seem to have been passed at appropriate intervals. At age 4 or 5 . mental retardation was noted. The first tics appeared at age 7 in the form of head jerks which soon spread to the upper limbs. At age 8 , he was hospitalized. The CSF, blood and urinary analysis, X-Rays of the skull and right carotid arteriography were within normal limits. Pneumoencephalography suggested a slight dilatation of the left lateral ventricle and the EEG showed signs of diffuse cerebral dysfunction. He was discharged with the diagnosis of mild debility associated with neurotic-tics, and was therefore treated with thioridazine until age 16 when he left the special school for retarded children. In spite of treatment, the tics continued unabated, the torso was involved and from time to time he emitted grunts. There was no family history of tics, but the patient's father had a seizure disorder. The neurological examination revealed sudden head twitches with rotation to the left, facial grimaces, jerky movements of the right arm and leg and leg squeezing motions. The EEG and blood tests were normal, except for increased alkaline phosphatase activity. Although he had professional and social adaptative problems, he did not seem motivated by the possible relief of his symptoms. He failed to return after the second month of clonazepam treatment, which had not produced any improvement.

\section{Case No. 7: S., F.}

This 14-year-old boy was the youngest of three children. No one in his family has tics. but his father has gout. His history includes caesarian birth and a normal, but slow, development. Onset of the disease was at age 3 with a number of tics: blinking, head twitch, dysarthria; many episodes resembling absence seizures followed by facial grimaces and eye blinking also developed. Previous EEG's were borderline and had shown no epileptic activity or temporal localization. Before the possibility of Gilles de la Tourette's syndrome was consi- dered a number of diagnoses were made including hyperactivity, emotional problems, seizures and autism. A variety of treatment were tried. Among these. methyl-phenidate caused an increase in tic frequency and intensity and haloperidol a transient benefit. When first seen in July, 1976. he showed a number of tics, various facial grimaces, eye blinking, absence attacks, hyperventilation, and much stereotyped behavior such as touching people and applauding. Verbalization was limited, restricted to unintelligible words and sounds. and it was difficult to evaluate the I.Q.. The child was hyperactive and only sat still for short periods. There was no coprolalia, but copropraxia was present. The neurological exam was otherwise normal. Because of distance and subsequent impossibility of regular follow-up, he was referred to a neurologist in his town, with the recommendation for a slow, gradually increased, combined therapy with haloperidol and clonazepam. Recent inquiry has revealed a definite improvement in most tics.

\section{DISCUSSION}

The preceding case reports are consistent with the diagnosis of Gilles de la Tourette's syndrome and include the clinical features required for the diagnosis as well as those confirmatory, but not essential aspects (Shapiro et al., 1973; Gonce and Barbeau, 1977; Sweet et al., 1976; Abuzzahab and Anderson, 1974). In each case, there was a history of early onset (between 2 and 15 years of age) and multiple involuntary muscular and verbal tics. The syndrome appears to be chronic with natural periods of remission and exacerbation. Of importance is the changing pattern of symptoms, new tics slowly developing and replacing or being added to pre-existing ones. Obscene words and gestures and echo-phenomena (echolalia, echopraxia) may occur, but are not obligatory for the diagnosis. These cases gave us the opportunity to review and discuss some aspects which have been pointed out recently, but are not well known.

Five of our seven patients had a family history of tics and seizures were found in another family. Familial cases of Gilles de la Tourette's disease are rare, but occur often enough to suggest a possible direct genetic mode of transmission (Friel, 1973; Sanders, 1973; Abuzzahab et al., 1975; Lucas, 1973). Like numerous observers, we were impressed 
with the high occurrence of tics amongst the parents and siblings of Tourette's patients (Ascher, 1948; Salmi, 1961; Corbin, 1970; Corbett et al., 1969). Although imitation of parents is possible, a genetic predisposition to the disorder is more probable. On the other hand, there has been widespread speculation about possible precipitating factors (natal or post-natal damage, infectious disease, physical or psychological traumatic events), but none has been shown to have specific etiological significance (Abuzzahab, 1974; Woodrow, 1974). Those factors could act as revealers of the subjacent constitutional deficiency (Gonce and Barbeau, 1977). It is also possible, as proposed by Moldofsky et al. (1971), that Tourette's patients fall into two groups: a genetically determined metabolic disorder and an acquired condition related to physical and psychological trauma. The suggestion of these authors that haloperidol is less beneficial in the acquired form than in the genetic variety was not substantiated by Fernando's observations (Fernando, 1976) nor by our own. Nevertheless, the unpredictable response and tolerance to haloperidol as well as to CNS stimulants may reflect an etiological and biochemical diversity (Barbeau, 1975; Golden; 1976) which may be manifested in such things as the serum uric acid levels.

Although we think that haloperidol is the best available therapy of multiple tic disorders, our own experience with this drug was not encouraging. There was a loss of efficacy (cases 2 . 3,4 and 7) and frequent intolerance (even with very gradually increased dosage or association with anticholinergic agents; cases 1, 3 and 4). This led us to try chonazepam, a new benzodiazepine, useful in the treatment of some forms of epilepsy (Browne, 1976). Because of the naturally fluctuating course of the illness and the preliminary nature of our observations in this study, it would be premature to form any definite conclusions concerning the use of clonazepam in the treatment of Gilles de la Tourette's disease. Nevertheless, the clear-cut improvement (mainly of vocalizations) shown by some patients (cases 2, 3 and 4) and the possible beneficial effects in two others (cases 1 and 7) are sufficient to suggest the use of clonazepam as adjunct therapy in Gilles de la Tourette's syndrome and lead to controlled, therapeutic, trials in other patients.

Moreover, these preliminary studies give indirect pharmacological insight into the role of serotonin in the cause or treatment of the tics of Tourette's disease, since there is recent evidence that clonazepam may act through modifications of the metabolism of this amine. Brain serotonin levels have been reported to be decreased in intention myoclonus, an entity successfully treated with 5-hydroxytryptophan, the serotonin precursor (L'Hermitte et al., 1971; Van Woert and Sethy, 1975a, b) and also with clonazepam (Bourdouresque et al., 1971; Goldberg and Dorman, 1976). In addition, the simple tics of Gilles de la Tourette's syndrome have clinical and electromyographic similarities to myoclonic muscle movements (Moldofsky, 1971).

Some authors have stressed the clinical and biochemical similarities between multiple tic disorder and Lesch-Nyhan syndrome (Moldofsky et al., 1974; Seegmiller, 1968; Van Woert et al., 1976). The latter is an $\mathrm{X}$-linked recessive disorder associated with a deficiency of the enzyme hypoxanthineguaninephosphoribosyl transferase (HGPRT'ase). Normally, this enzyme plays an important role in the reutilization metabolic pathway of uric acid and is found in high concentration in the basal ganglia. In addition to the manifestations of gout, the cardinal features of the syndrome are mental retardation, spastic cerebral palsy, jerking and choreoathetosic movements. aggressive behavior and selfmutilations. The vocal components are also characteristic: grunts, cries and obscenities (Nyham, 1972).

Self destructive behavior occurred in $40-50 \%$ of the 114 Tourette's patients reviewed by Van Woert et al. (1976). The serum uric acid is sometimes increased in these patients. who often have a family history of gout or hyperuricemia in one or more mem- bers (Van Woert et al., 1976; Pfeiffer et al., 1969). Our observations also confirm these facts. Such similarities led Van Woert et al. (1976) to suggest that Tourette's syndrome could be a genetic disorder of purine metabolism which may result in neuro-transmitter abnormalities. As Mizumo and Yugari (1974) reported, L-5-hydroxytryptophan (L-5-HTP) reduced self mutilation in 4 children with Lesch-Nyhan's syndrome. They treated one Tourette's patient with the combination L-5THPcarbidopa and noted a subsequent significant reduction in the tics and self-mutilations. This improvement disappeared when a placebo was substituted.

The apparent favorable results with clonazepam reported in our study may also be related to modifications of brain serotonin. Clonazepam has been shown to increase cerebral 5-hydroxytryptamine content in mice, and this effect has been invoked to explain the antimyoclonic properties of the drug (Jenner et al., 1975; Chadwick, 1975), although its action is not unequivocal (Fennessy and Lee, 1972).

Because of the preliminary nature of these studies, one may not draw any definite conclusion on the exact role of serotonin in the pathophysiology and treatment of multiple tic disorder. This working hypothesis needs confirmation, particularly as 5-HIAA (the major metabolite of serotonin) was found to be normal in Tourette's patients' CSF (Sweet et al., 1976; Van Woert et al., 1976; Cohen et al., 1974), and L-tryptophan, another precursor of serotonin, was ineffective for tics (Sweet et al., 1976). Finally, Moldofsky et al. (1974) measured GHPRT' ase activity in two patients with Tourette's syndrome and found it to be normal.

Moreover, disturbances in other neurotransmitters in association with Tourette's syndrome have been invoked and recently reviewed by Sweet et al. (1976). The hypothesis that Tourette's symptoms are related to a central dopaminergic hyperactivit y merits consideration in view of the efficacy of the known dopamine receptor blocker: haloperidol. Like 
other extrapyramidal disorders, Gilles de la Tourette's syndrome may be the result of a pharmacological imbalance between the functions of many putative neurotransmitters (Barbeau, 1962). These disturbances are probably related only to the symptoms of the disease, and not to its cause.

\section{ACKNOWLEDGMENTS}

The above studies were made possible through partial support from the Medical Research Council of Canada (MT-4938), the United Parkinson Foundation and the $W$. Garfield Weston Foundation. The authors would like to thank Drs. Madeleine Roy and Raymonde Labrecque for their help in the clinic and Mrs. Monique Savard for typing the manuscript.

\section{REFERENCES}

$A B U Z Z A H A B$. F. S. and ANDERSON. F. O. (1974). Gilles de la Tourette's syndrome: Cross-cultural analysis and treatment outcome. Clin. Neurol. Neurosurg., 1. 66-74.

ABUZZAHAB, F. S.. ANDERSON, F. O. and SEKHOV, S. M. (1975). Multiple tic disorder: Gilles de la Tourette's syndrome. Practical Psychology for Physician. 2. 58-60.

ABAZZAHAB, F. S. and EHLEN, K. J. (1971). The clinical picture and management of Gilles de la Tourette's syndrome. Child Psychiatry and Human Development. 2, 14-25.

ASCHER, E. (1948). Psychodynamic considerations in Gilles de la Tourette's disease (maladie des tics). American Journal of Psychiatry. 105, 267-276.

BARBEAU. A. (1962). The pathogenesis of Parkinson's disease: A new hypothesis. Canadian Medical Association Journal, 87. 802-807.

BARBEAU. A. (1975). Maladies du système extrapyramidal. In: (Pequignot, H., ed.). Pathologie Médicale. Masson Cie, Paris. pp. 1446-1453.

BOURDOURESQUE, J., ROGER, J., KHALIL. R., VIROUROUX, R. A.. GOSSET. A.. PELLISER. J. F. and TASSINARI. C. A. (1971). La maladie de Gilles de la Tourette. Revue Neurologique. 125. 306-309.

BROWNE. R. D. (1976). Clonazepam. A review of a new anticonvulsant drug. Arehives of Neurology, 33, 326-332.

BRUUN. R. D. and SHAPIRO. A. K. (1972). Differential diagnosis of Gilles de la
Tourette's syndrome. Journal of Nervous and Mental Diseases, 155, 328-334.

CHADWICK, D., HARRIS, R., JENNER, P., REYNOLDS, E. H. and MARSDEN, C. D. (1975). Manipulation of brain serotonin in the treatment of myoclonus. Lancet, 1, 434-435, 1975.

CHAPEL, J. L., BROWN, N. and JENKINS, R. L. (1964). Tourette's disease: Symptomatic relief with haloperidol. American Journal of Psychiatry, 121, 608-610.

COHEN, D. J., SHAYWITZ, B. A., JOHNSON, W. T. and BOWERS, R. Jr. (1974). Biogenic amines in autistic and atypical children. Archives of General Psychiatry, 31, 845-853.

CORBETT, J. A., MATTHEWS, A. M., CONNELL, P. H. and SHAPIRO, D. A. (1969). Tics and GTS: A follow-up study and critical review. British Journal of Psychiatry, 115, 1229-1241.

CORBIN, K. B. (1970). GTS: Common neurophysiologic factors reported in literature. New York State Journal of Medicine, 70, 2193-2197.

DiGI ACOMO, J. N.. FAHN, S., GLASS, J. B. and WESTLAKE, R. J. (1971). A case with GTS treated with haloperidol and unsuccessful treatment with L-Dopa. Journal of Nervous and Mental Diseases, 152 . 115-117.

FENNESSY, M. R. and LEE, J. R. (1972). The effect of benzodiazepines on brain amines of the mouse. Archives Internationales de Pharmacodynamie et de Thérapie, 197, 37-44.

FERNANDO, S. J. M. (1976). Six cases of Gilles de la Tourette's syndrome. British Journal of Psychiatry. 128. 436-441.

FRIEL. P. B. (1973). Familial incidence of Gilles de la Tourette's disease. British Journal of Psychiatry. 112. 655-658.

GOLDBERG. M. A. and DORMAN. J. D. (1976). Intention myoclonus: successful treatment with clonazepam. Neurology. 26. 24-26.

GOLDEN. G. S. (1976). Tourette's syndrome and central nervous system stimulants. Presented at the 28th Annual Meeting of the American Academy of Neurology. April 26-May 1, 1976.

GONCE. M. and BARBEAU. A. (1977). La maladie de Gilles de la Tourette. Union Médicale du Canada. 106, 559-570.

JENNER. P. . CHADWICK. D.. REYNOLDS, E. H. and MARSDEN, C. D. (1975). Altered 5-HT metabolism with clonazepam, diazepam and diphenylhydantoin. Journal of Pharmacy and Pharmacology. 27. 707-710.

L'HERMitTe, F.. PETERFalvi, M. and MARTEAU. R. (1971). Analyse pharmacologique d'un cas de myoclonies d'intention et d'action post-anoxiques. Revue Neurologique. 124, 21-31.

LUCAS. A. R. (1973). Report of GT's disease in two succeeding generations. Child Psychiatry Human Development. 3. $321-323$.
MIZUMO, T. and YUGARI. Y. (1974), Self-mutilation in Lesch-Nyhan syndrome, Lancet, Vol T: 761.

MOLDOFSKY, H. (1971). A psychophysiological study of multiple tics. Archives of General Psychiatry. 25. 79-87.

MOLDOFSKY. H., TULLIS. C. and LAMON, R. (1974). Multiple tic syndrome (Gilles de la Tourette's syndrome). Journal of Nervous and Mental Diseases, 159. 252-292.

NYHAN, W. L. (1972). Clinical features of the Lesh-Nyhan syndrome. Archives of Internal Medicine. 130. 186-192.

PFEIFFER, C. C.. ILIEV, V.. NICHOLS, R. E. and SUGERMAN, A. A. (1969). The serum urate level reflects degrees of stress. Journal of Clinical Pharmacology. 9. 384-392.

SALMI. K. (1961). Gilles de la Tourette's disease: The report of a case and its treatment. Acta Psychiatrica et Neurologica Scandinavica, 36, 157-162.

SANDERS, D. G. (1973). Familial occurrence of GTS. Archives of General Psychiatry, 28, 326-328.

SEEGMILLER, J. G. (1968). The discussion of pathology and pathologic physiology of Lesch-Nyhan syndrome. Federation Proceedings, 27, 1044-1046.

SEIGNOT, J. N. (1961). Un cas de maladie des tics de Gilles de la Tourette guéri par le R-1625. Annales Médico-Psychologiques. 119. 578.

SHAPIRO. A. K., SHAPIRO, E. and WAYNE. H. (1973). Treatment of Tourette's syndrome with haloperidol. Review of 34 cases. Archives of General Psychiatry. 28, 92-97.

SHAPIRO. A. K., SHAPIRO. E. and WAYNE. H. L. (1973). The symptomatology and diagnosis of Gilles de la Tourette's syndrome. Journal of The American Academy of Child Psychiatry, 12, 702-723.

SWEET. R. D.. BRUUN, R. D.. SHAPIRO. A. K. and SHAPIRO. E. (1976) The pharmacology of Gilles de la Tourette's syndrome (chronic multiple tic). In: (Klawans. H. L.. ed.). Clinical Neuropharmacology. Raven Press. New York. pp. 81-105.

VAN WOERT, M. H., JUTKOWITZ, R.. ROSENBAUM, D and BOWERS. M. B.. Jr. (1976). In: (Yahr. M. D.. ed.). The Basal Ganglia: Association for Research in Nervous and Mental Disease. Vol. 55. Raven Press. New York. pp. 459-465.

VAN WOERT. M. H. and SETHY. V. H. (1975). Therapy of intention myoclonus with L-5-hydroxytryptophan and a peripheral decarboxylase inhibition. MK-486. Neurology. 25, 135-140.

VAN WOERT, M. H. and SETHY, V. H. (1975). Therapy of myoclonus with L-5-hydroxytryptophan plus MK-486. Neurology, 25, 362.

WOODROW. K. M. (1974). Gilles de la Tourette's disease. A review. American Journal of Psychiatry, 131. 1000-1003. 